\title{
The effect of increasing levels of fish oil on some immune responses of broiler chickens
}

\author{
H. S. Al-Khalifa ${ }^{1}$, C. Rymer ${ }^{1}$, I. Givens ${ }^{1}$ and P. Yaqoob ${ }^{2}$ \\ ${ }^{1}$ Department of Agriculture, The University of Reading, UK and ${ }^{2}$ Department of Food Biosciences, The University of \\ Reading, $U K$
}

There has been some interest in the enrichment of poultry meat with long-chain $n-3$ PUFA as a means of increasing the low consumption of these acids by human subjects consuming western diets. There is some concern, however, that at high levels of consumption, $n$ - 3 PUFA may have detrimental effects on immune function. However, research to date shows that strong controversy surrounds this immunomodulation. The aim of this experiment was to determine the effects of dietary long-chain PUFA on some aspects of immune function in broiler chickens. A total of 18 one-day-old male Ross 308 broiler chicks were reared as a single group for $21 \mathrm{~d}$, and fed a common starter diet. At $21 \mathrm{~d}$, the broilers were then fed for $33 \mathrm{~d}$ one of three wheat-soyabean meal-based diets. All diets contained $60 \mathrm{~g} / \mathrm{kg}$ added oil, which was either 0,$60 ; 30,30$; or $60,0 \mathrm{~g}$ fish oil (FO) and soya oil, respectively. Chickens between 54 and $60 \mathrm{~d}$ of age were sacrificed and samples of blood, bursa of Fabricus, spleen and thymus were collected. The lymphocytes were stained with four monoclonal antibodies: anti-CD3, anti-CD4, anti-CD8 and BU-1A. Immune cells were then enumerated using the FACSCalibur ${ }^{\mathrm{TM}}$ flow cytometer. The quantitative analysis of the phagocytic activity of peripheral mononuclear phagocytes in whole blood was performed using phagotest commercial kits. Increasing levels of FO did not affect the weights of the spleen. However, chickens fed diet with $60 \mathrm{~g} / \mathrm{kg}$ FO had significantly lower bursa weights $(P<0.01)$ than those fed diets with 0 and $30 \mathrm{~g} / \mathrm{kg}$ FO. In addition, the bursae were thinner compared with bursae from chickens fed diets containing less FO (Table 1). Chickens fed diets containing $30 \mathrm{~g} / \mathrm{kg}$ FO had significantly higher thymus weights compared to chickens fed 0 and $60 \mathrm{~g} / \mathrm{kg}(P<0.05)$. There was no significant effect of increasing FO level on the percentage positive and mean fluorescence intensity (MFI) of the leucocyte subsets in peripheral blood, spleen and thymus. However, the proportion of B-cells in peripheral blood and the MFI of CD8 subsets in the spleen approached significance, $P=0.058$ and 0.054 , respectively. Results of phagocytic activity show that the different levels of FO in the experimental groups neither affected the positive percentage of cells nor MFI. However, there was a trend towards a lower proportion of monocytes being engaged in phagocytosis when broilers were fed diets containing $60 \mathrm{~g} / \mathrm{kg}$ FO $(P=0.055)$ (Table 2).

Table 1. \% Body weight of different tissues

\begin{tabular}{|c|c|c|c|c|}
\hline \multirow{2}{*}{ Diet $(\mathrm{g} / \mathrm{kg} F O)$} & \multicolumn{4}{|c|}{ Tissue $^{1}$} \\
\hline & \multicolumn{2}{|c|}{ Spleen } & Thymus & Bursa \\
\hline 0 & \multicolumn{2}{|c|}{0.12} & $0.15^{\mathrm{a}}$ & $0.30^{\mathrm{a}}$ \\
\hline 30 & \multicolumn{2}{|c|}{0.15} & $0.17^{\mathrm{b}}$ & $0.28^{\mathrm{a}}$ \\
\hline 60 & \multicolumn{2}{|c|}{0.12} & $0.12^{\mathrm{a}}$ & $0.14^{\mathrm{b}}$ \\
\hline SEM & \multicolumn{2}{|c|}{0.01} & 0.01 & 0.02 \\
\hline$P$ value & \multicolumn{2}{|c|}{0.164} & 0.022 & 0.001 \\
\hline \multicolumn{5}{|c|}{${ }^{1}$ For each tissue weight $\%$, values with different superscripts are significantly different. } \\
\hline & \multicolumn{2}{|c|}{ Monocytes } & \multicolumn{2}{|c|}{ Granulocytes } \\
\hline Diet ( $\mathrm{g} / \mathrm{kg}$ FO) & $\%$ of + ve cell & MFI & $\%$ of + ve cells & MFI \\
\hline 0 & 46.78 & 2148 & 69.77 & 1737.9 \\
\hline 30 & 48.76 & 2306 & 82.34 & 3448.5 \\
\hline 60 & 35.16 & 2044.4 & 72.84 & 2204 \\
\hline S.E.M. & 3.788 & 630.32 & 3.76 & 992.33 \\
\hline$P$ value & 0.055 & 0.962 & 0.102 & 0.267 \\
\hline
\end{tabular}

Conclusions. These results show no evidence of the detrimental effect of enrichment with FO under the circumstances of this study. However, more subsequent studies should be conducted on different immune functions under different situations (e.g. challenge with pathogen), especially as there is evidence of a potential threshold effect in some cases. Such studies would help the poultry industry to improve or maintain the health status of poultry at an optimum level in circumstances when poultry meat is being enriched with longchain $n$-3 PUFA.

The authors gratefully acknowledge funding from Kuwait Institute for scientific research. 